\title{
After GAVI pledges surpass goals, focus shifts to keeping promises
}

LONDON - In a move that surpassed expectations given the tough economic times, donors committed $\$ 4.3$ billion to the GAVI Alliance at a 13 June pledging conferenceexceeding the target of $\$ 3.7$ billion. The funds secure the next five-year chapter of the Geneva-based public-private partnership aimed at stamping out preventable illness in the world's poorest countries-in particular, two of the biggest child killers, pneumonia and diarrhea.

"Now poor kids will get the vaccines that rich kids get," Bill Gates, whose Bill \& Melinda Gates Foundation is slated to give GAVI more than $\$ 1$ billion, said at the meeting here.

Some of the largest government pledges came from the UK ( $\$ 1.3$ billion), Norway (\$819 million) and France (\$511 million). Notably, the current framework is such that approximately $85 \%$ of GAVI support is in-kind donations of materials such as vaccines.
Looking ahead, the organization is pushing to shape vaccine markets and drive down prices by involving more developingworld-based pharmaceutical companies in vaccine research and manufacturing. But there are some voices that are doubtful of GAVI pushing enough to reduce the costs of vaccines.

"Of course government donors need to support GAVI, but they need to make their support conditional on GAVI using its buying power to foster competition and to push for adapted products," Daniel Berman of Médecins Sans Frontières in Geneva, told Nature Medicine.

Furthermore, in most countries, parliamentary approval will be required before the pledges turn into real funding. This, along with other factors, can throw a wrench in the pledge figures.

"There is absolutely no correspondence, apart from wishful thinking, that connects commitments with disbursements," says public health commentator Amir Attaran of the University of Ottawa. "Donors are in the bad habit of reannouncing money that has already been committed once it is committed again at a later date for publicity."

The misappropriation of funds at a country level is another financial challenge, as evidenced by revelations this past March of such problems in GAVI-supported programs in several countries.

However, according to Stéfanie Laniel from the GAVI Alliance secretariat, "vaccines represent a low risk of misuse compared to cash payments or other medicines for which there is a secondary market."

"Vaccines are lower in value than other medical commodities - and because vaccines are preventive rather than curative medicines, there is less incentive for their misuse," Laniel adds.

Georgina Kenyon

\section{France adds weight to obesity research with new institute}

PARIS - Despite the idea of the so-called 'French paradox' that refers to the relatively slender waistlines in France vis-à-vis the country's rich foods, the nation is not immune to the worldwide obesity epidemic. According to French officials, 15\% of the population is obese, and the numbers are rising. Faced with this reality, a new national obesity plan is in the works, making this area a top research priority for France in the upcoming years.

On 25 May, France's Ministry of Higher Education and Research announced a commitment of $€ 130$ million ( $\$ 185$ million) as

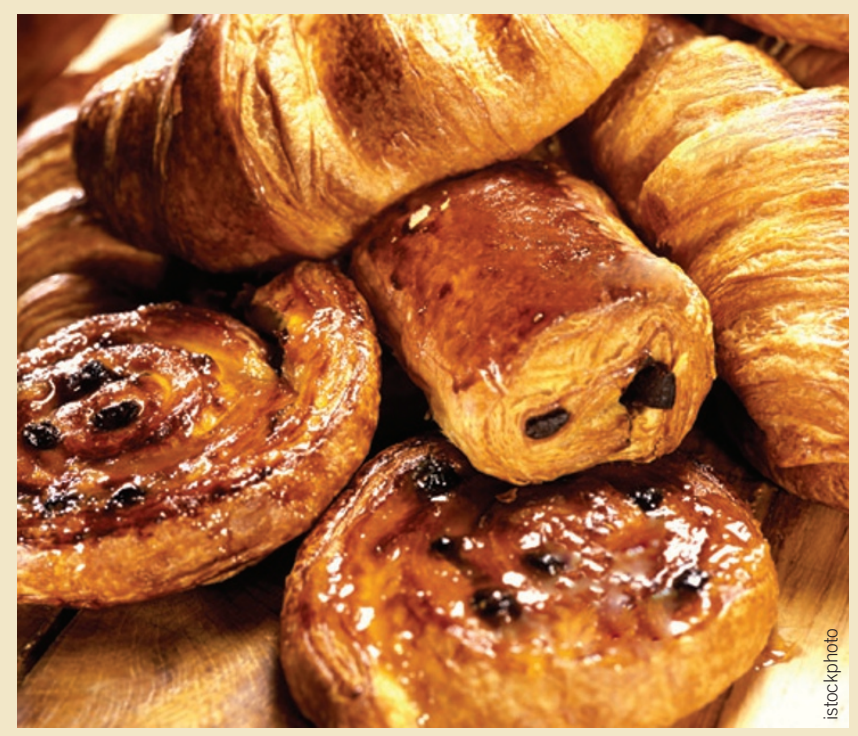

part of its future investment scheme dedicated solely toward obesity-related research. The sum, which will be dispensed over the next decade, represents a substantial increase over previous government plans to boost research in this field.

"Research spending will comprise one of three pillars of the plan, which will also include prevention and the provision of specialized point-of-care centers," Arnaud Basdevant, a nutritionist at the helm of the plan, told Nature Medicine.

Front and center in the scheme is the launch of a new obesity foundation by the end of this year that will be a public-private partnership under the stewardship of the French National Alliance for Life Sciences and Health (AVIESAN), which groups together the main biomedical stakeholders in the country. The new foundation will most likely be based in Paris and modeled on what has previously been done in the area of Alzheimer's disease, for which France created a specific thematic foundation in 2008 to help coordinate research.

Claude Jaffiol, an endocrinologist at the University Hospital of Montpellier and a member of the French Academy of Medicine, says he expects the increased investment to lead to some "interesting new outcomes" in the field. However, he is less sanguine about whether the new cash flow alone will elevate the position of France as a major international hub for innovation.

As for the specific industrial partners that will join the new foundation, this is currently in the phase of negotiations. "The food industry will most likely play the main role," says JeanMichel Heard, who oversees the department for biology and health at the government's funding agency, the National Research Agency (ANR).

Pain au chocolat: Obesity hurts $15 \%$ of France.

Karen Dente 